\title{
Analysis of selected serological parameters in patients with diagnosed Lyme borreliosis and in seropositive patients with no clinical symptoms
}

\author{
Małgorzata Tokarska-Rodak ${ }^{1, A, C-F \oplus}$, Anna Pańczuk ${ }^{1, C-E \oplus}{ }^{\oplus}$ Hanna Fota-Markowska ${ }^{2,3, A-B, F \oplus}$, \\ Katarzyna Matuska ${ }^{4, B-c} \bullet$ \\ ${ }^{1}$ Faculty of Health Sciences, Pope John Paul II State School of Higher Education, Biala Podlaska, Poland \\ ${ }^{2}$ Institute of Rural Health, Lublin, Poland \\ ${ }^{3}$ Department of Infectious Diseases, Skubiszewski Medical University, Lublin, Poland \\ ${ }^{4}$ Department of Microbiological Diagnostics Clinical Hospital No. 1, Lublin, Poland \\ $A$ - Research concept and design, B - Collection and/or assembly of data, C - Data analysis and interpretation, \\ $D$ - Writing the article, E - Critical revision of the article, F - Final approval of article
}

Tokarska-Rodak M, Pańczuk A, Fota-Markowska H, Matuska K. Analysis of selected serological parameters in patients with diagnosed Lyme
borreliosis and in seropositive patients with no clinical symptoms. Ann Agric Environ Med. 2021; 28(3): 397-403. doi: 10.26444/aaem/124088

\section{Abstract}

Objectives. The aim of the study was to analyze some metalloproteinases, cytokines, and chemokines in LB patients and healthy seropositive subjects. The presence of $\mathrm{IgM} / \mathrm{lgG}$ antibodies against specific Borreliella antigens was analyzed in the presence or absence of clinical manifestations of LB.

Materials and method. The study involved 38 patients diagnosed with $L B$ and arthralgia and/or arthritis symptoms, and 57 foresters presenting no clinical symptoms of LB. The ELISA test was applied for general screening of anti-Borreliella $\mathrm{IgM} / \mathrm{lgG}$. Western blot was used for confirmatory diagnosis of LB for the positive and borderline results. Serum IL-2, IL-4, IL-6, IL-10, IL-17A, IFN-, , TNF, IL-8, CCL5, CXCL9/MIG, CCL2/MCP-1, CXCL10/IP-10 concentrations were measured with the use of the Human Cytometric CBA test. The concentration of MMP-2 and MMP-9 in the serum was determined with the use of ELISA tests.

Results. Analysis of the cytokines and chemokines revealed that only the concentration of IL-2 was significantly higher (2.4 $\mathrm{pg} / \mathrm{m} ; \mathrm{p}=0.00641)$ in patients with LB symptoms than in the seropositive individuals $(0.4 \mathrm{pg} / \mathrm{ml})$. The MMP2 concentration was significantly higher $(233.3 \mathrm{ng} / \mathrm{ml} ; \mathrm{p}=0.00294)$ in patients with clinical manifestations of $L B$ than in those occupationally exposed to tick bites, but did not have anti-Borreliella antibodies (192.0 ng/ml).

Conclusions. The presence of IgG antibodies against a number of Borreliella antigens and the differences in the IL-2 and MMP2 levels in seropositive or seronegative individuals and symptomatic LB patients, may indicate differences in the intensity of the immune response to the infection and, consequently, may induce development of clinical manifestations of the disease in seropositive and seronegative individuals.

\section{Key words}

cytokines, MMP-9, MMP-2, Lyme borreliosis, Borreliella

\section{INTRODUCTION}

Lyme borreliosis (LB) is caused by spirochetes of the Lyme Disease (LD) group of the Borreliaceae species which are transmitted by ticks [1]. LB is a disease with diverse clinical presentations the most common of which is the manifestation of erythema migrans (EM). However, the infecting pathogen can spread to other tissues and organs, causing more severe manifestations involving the patient's skin, nervous system, joints, or heart $[2,3,4]$.

More than 10 genospecies are included to LD group of Borreliaceae species: Borreliella afzelii, Borreliella garinii, Borreliellabavariensis, Borreliellaburgdorferi, and occasionally Borreliella spielmanii and Borreliella lusitaniae, are pathogenic to humans in Europe, whereas Borreliella burgdorferi and, in certain areas, Borreliella mayonii, are human pathogens in North America $[1,5]$. The spirochetes B. afzelii is mostly associated with skin manifestations and $B$. garinii and

Address for correspondence: Anna Pańczuk, Faculty of Health Sciences, Pope John Paul II State School of Higher Education, Biala Podlaska, Poland

E-mail: anna.panczuk@poczta.onet.pl

Received: 25.03.2020; accepted: 17.06.2020; first published:08.07.2020
B. burgdorferi seem to be the most neurotropic and the most arthritogenic species, respectively [3].

In accordance with current recommendations, the presence of at least one of the clinical symptoms: erythema migrans, borrelial lymphoma, and acrodermatitis chronica athrophicans, or a set of symptoms comprising Lyme carditis, Lyme arthritis, and neuroborreliosis, is the basis for the diagnosis of Lyme borreliosis. Another indispensable element of diagnostics (besides EM skin lesions localized early) is the detection of specific anti-Borreliella antibodies. Laboratory diagnostics consists of two stages: detection of specific antibodies with the enzyme immunoassay and confirmation with the Western blot test $[6,7,8]$.

An interesting phenomenon is the presence of specific antiBorreliella antibodies without clinical signs of infection [9-19]. Detection of antibodies alone does not evidence the disease $[5,7]$. The reasons why some patients present clinical signs of Lyme borreliosis while others only undergo seroconversion are not fully known. It seems that the type of generated immune reactions may have key importance for the development of Lyme borreliosis. Neutrophils, acidophils, mast cells, and macrophages are involved in the immune response against 
of Borreliella species. The inflammatory response mediators produced by these cells, as well as the synergistic interactions of macrophages and T cells, influence the intensity of immune response to infection [20]. B. burgdorferi spirochetes do not secrete enzymes degrading the extracellular matrix that would facilitate entrance into the host organism and migration in tissues [21]. However, they are able to activate proteolytic enzymes, e.g. matrix metallproteinases (MMPs), and thus penetrate human tissues [22]. Metalloproteinases are involved in degradation of protein components of the extracellular matrix and hydrolysis of molecules released from the cell surface. Thus, they can activate or inactivate many cytokines, chemokines, and growth factors [23,24]. Cytokines secreted by activated $T$ cells have a considerable impact on the regulation and effectiveness of immune response. Th1 cells secrete IFN- $\gamma$ and TNF, thus promoting cytotoxic phagocytedependent immune response. In turn, Th2 cells secrete IL-4, IL-5, and IL-9 inducing humoral phagocyte-independent immune response [10].

\section{OBJECTIVES}

The aim of the study is to analyze some serological parameters (metalloproteinases, cytokines, and chemokines) in Lyme borreliosis patients and healthy seropositive subjects. The presence of IgM/IgG antibodies against specific Borreliella antigens was analyzed in the presence or absence of clinical manifestations of Lyme borreliosis.

\section{MATERIALS AND METHODS}

Study group. The examinations involved 95 subjects, including: 38 patients diagnosed with Lyme borreliosis and arthralgia and/or arthritis symptoms, who were patients in the Clinic for Infectious Diseases at the Medical University, in Lublin, eastern Poland. The diagnosis was based on medical history, physical examination, clinical picture, and serological tests in accordance with the recommended procedure for Lyme borreliosis diagnosis [7]. The patient group included 22 females and 16 males between the ages of $21-80$, average age - 57 (SD 13.3), and 57 foresters occupationally exposed to tick bites, presenting no clinical symptoms of Lyme borreliosis. The 3 females and 54 males in this group were between the ages of $26-70$, average age 49 (SD 9.8). They worked in the forest districts of Lublin Province of eastern Poland.

Information on tick bites was collected from all 95 subjects. Serological tests were carried out to detect the presence of anti-Borreliella $\operatorname{IgM} / \mathrm{IgG}$ antibodies, and selected serological parameters (metalloproteinases and cytokines) were analyzed. In the patient group, blood was collected for testing before application of the treatment (2017 - 2018). Blood was collected from the foresters in 2014-2015.

Serological tests. The presence of anti-Borreliella IgM/ IgG antibodies was assessed in accordance with the recommendations in a two-stage diagnostic scheme: the first stage - ELISA tests and the second stage - confirmation Western blot tests in the case of a positive or borderline result obtained in the first diagnostic stage $[6,7,8]$.

Anti-Borrelia ELISA IgM and anti-Borrelia plus VlsE ELISA IgG (Euroimmun, Germany) were used in the study.
The reaction wells were coated with a mixture of antigens derived from B. burgdorferi, B. afzelii, and B. garinii, as well as the recombinant $B$. burgdorferi $\mathrm{VlsE}$ antigen. Results below 16 relative units/ml (RU/ml), between $16-22 \mathrm{RU} / \mathrm{ml}$, and above $22 \mathrm{RU} / \mathrm{ml}$ were regarded as negative, borderline, and positive, respectively.

The Western blot Anti-Borrelia EUROLINE-WB IgM test (Euroimmun, Germany) was used for confirmation of the positive and borderline IgM results. The test strips contained a complete $B$. afzelii antigen extract and a membrane chip with recombinant VlsE antigen. In the IgG class, an Anti-Borrelia EUROLINE-RN-AT-IgG kit (Euroimmun, Germany) was employed as a confirmation test. The test strips contained highly specific recombinant $B$. burgdorferi s.s. antigens (p83, p58, p21, p20, p19, p18), highly specific recombinant dimeric OspC (advance, p25) from B. burgdorferi, B. garinii, and B. afzelii, purified recombinant flagellin (p41) and BmpA (p39) from B. afzelii, Borrelia afzelii lipid (LBa), B. burgdorferi. lipid, and highly purified recombinant VlsE antigens.

Serological parameters: cytokines and metalloproteinases. Serum IL-2, IL-4, IL-6, IL-10, IL-17A, IFN- $\gamma$, and TNF concentrations were measured with the use of the Human Cytometric Bead Array Kit Th1/Th2/Th17 test (Becton Dickinson; BD). The level of IL-8 (CXCL8), CCL5 (RANTES, Regulated on Activation, Normal T-cell Expressed and Secreted), monokine induced by interferon gamma (CXCL9/ MIG), monocyte chemoattractant protein-1 (CCL2/MCP1), and interferon gamma-induced protein-10 (CXCL10/ IP-10) in serum samples were determined using the Human Chemokine I Cytometric Bead Array Kit (Becton Dickinson; BD). Equipment: FACSCanto ${ }^{\mathrm{TM}}$ II cytometer and FCAP Array $^{\mathrm{TM}}$ Software Version 3.0. (Becton Dickinson; BD).

The concentration of MMP-2 in the serum was determined (ELISA, R\&D): a monoclonal antibody specific for MMP-2 has been pre-coated onto a microplate. Standards and samples were pipetted into the wells and any MMP-2 present was bound by the immobilized antibody. Minimum detectable dose (MDD) of MMP-2 ranged from $0.014-0.082 \mathrm{ng} / \mathrm{mL}$. The concentration of MMP-9 in the serum was determined (EISA, $\mathrm{R} \& \mathrm{D})$ : a monoclonal antibody specific for human MMP-9 has been pre-coated onto a microplate. Standards and samples were pipetted into the wells, and MMP-9 was bound by the immobilized antibody. The minimum detectable dose (MDD) of human MMP-9 is typically less than $0.156 \mathrm{ng} / \mathrm{mL}$.

Equipment: ELISA plate reader (Thermo Scientific). All serological assays were carried out and results were interpreted according to the manufacturers' instructions. The data were analyzed statistically using the Statistica v.10 programme. The Mann-Whitney U test and the KruskalWallis test were employed to determine the statistical significance of the results. Values of $\mathrm{p}<0.05$ were considered statistically significant.

The Bioethical Committee of the Medical University in Lublin authorized the project (Permission No. KE0254/177/2014; KE-0254/27/2016).

\section{RESULTS}

Tick bite episodes. Tick bites were reported by 30 of the 38 patients with clinical manifestations of Lyme borreliosis 
(79\%). A single bite was declared by 6 patients (16\%), whereas 24 subjects (63\%) reported multiple events. Eight Lyme borreliosis patients (21\%) had not noticed any tick bites.

In the group of the 57 examined foresters, 43 (75\%) workers reported tick bites, with 11 individuals who had been bitten once, and $32(56 \%)$ subjects declaring multiple attacks. No tick infestations were declared by 14 (25\%) foresters.

Anti-B. burgdorferi antibodies. In all patients with clinical manifestations of Lyme borreliosis (38 persons), ELISA results were confirmed by Western blot tests. The presence of anti-Borreliella antibodies by Western blot was confirmed in 33 foresters (57.9\%).

Antibodies against specific Borreliella antigenic proteins were detected in all patients: 2 of them (5.3\%) had IgM class antibodies, 9 patients $(23.7 \%)$ had IgM and IgG class antibodies, and 27 subjects (71\%) had IgG class antibodies. IgM antibodies for the p25 antigen were detected most frequently (28.9\% of the patients), whereas IgG for the VlsE and p41 antigens were usually found (94.7\% of the patients). Detailed data on the presence of anti-Borreliella IgM/IgG are shown in Table 1.

Table 1. Anti-Borreliella IgM/lgG antibodies in patients with clinical manifestations of Lyme borreliosis

\begin{tabular}{|c|c|c|c|c|c|}
\hline \multirow{2}{*}{\multicolumn{2}{|c|}{$\begin{array}{l}\text { Anti- } \\
\text { Borreliella } \\
\text { IgM/lgG } \\
\text { antibodies }\end{array}$}} & \multicolumn{4}{|c|}{$\begin{array}{l}\text { Patients with Lyme borreliosis } \\
\qquad \mathrm{N}(\%)\end{array}$} \\
\hline & & $\begin{array}{l}\text { Patients with } \\
\text { IgM antibodies } \\
\text { present }\end{array}$ & $\begin{array}{c}\text { Patients with } \lg M \\
\text { and IgG antibodies } \\
\text { present }\end{array}$ & $\begin{array}{l}\text { Patients with } \\
\text { IgG antibodies } \\
\text { present }\end{array}$ & Total \\
\hline \multirow{6}{*}{$\lg M$} & p17 & - & $1(2.6)$ & - & $1(2.6)$ \\
\hline & p25 & $2(5.3)$ & $9(23.7)$ & - & $11(28.9)$ \\
\hline & p31 & - & $2(5.3)$ & - & $2(5.3)$ \\
\hline & p39 & - & $1(2.6)$ & - & $1(2.6)$ \\
\hline & 83 & - & $1(2.6)$ & - & $1(2.6)$ \\
\hline & VlsE & - & $1(2.6)$ & - & $1(2.6)$ \\
\hline \multirow{12}{*}{ IgG } & $\mathrm{p} 18$ & - & - & $5(13.1)$ & $5(13.1)$ \\
\hline & p19 & - & $2(5.3)$ & $5(13.1)$ & $7(18.4)$ \\
\hline & p20 & - & $1(2.6)$ & $1(2.6)$ & $2(5.3)$ \\
\hline & p21 & - & $2(5.3)$ & $4(10.5)$ & $6(15.8)$ \\
\hline & p25 & - & $7(18.4)$ & $8(21.0)$ & $15(39.5)$ \\
\hline & p39 & - & $1(2.6)$ & $8(21.0)$ & $9(23.7)$ \\
\hline & p41 & - & $9(23.7)$ & $27(71.0)$ & $36(94.7)$ \\
\hline & p58 & - & $1(2.6)$ & $5(13.1)$ & $6(15.8)$ \\
\hline & p83 & - & $3(7.9)$ & $8(21.0)$ & 11(28.9) \\
\hline & VlsE & - & $9(23.7)$ & $27(71.0)$ & $36(94.7)$ \\
\hline & Lba & - & $1(2.6)$ & $2(5.3)$ & $3(7.9)$ \\
\hline & Lbb & - & $1(2.6)$ & $1(2.6)$ & $2(5.3)$ \\
\hline \multicolumn{2}{|l|}{ Total } & $2(5.3)$ & $9(23.7)$ & $27(71.0)$ & $38(100.0)$ \\
\hline
\end{tabular}

$\mathrm{N}$ - Number of people in the test group

No anti-Borreliella IgM antibodies were detected in any of the examined foresters. In this group, anti-Borreliella IgG antibodies were found in the case of 33 (57.9\%) but not in the other 24 forest workers $(42.1 \%)$. No person from this group declared any clinical symptoms of Lyme borreliosis.

The prevalence of the specific Borreliella IgG antibodies was compared between the groups of the seropositive foresters and patients with advanced (IgM and $\operatorname{IgG}$ ) and late (IgG only) anti-Borreliella response (Tab. 2). Patients with Lyme borreliosis symptoms exhibited a significantly higher level of anti-p25 IgG ( $\mathrm{p}=0.00009)$, anti-VlsE IgG ( $\mathrm{p}=0.000001)$, and anti-p41 IgG ( $\mathrm{p}=0.000001)$ antibodies than that determined in the group of the seropositive foresters. In turn, anti-p18 IgG antibodies were detected in the sera of the seropositive foresters, with a significantly higher frequency than in the Lyme borreliosis patients $(\mathrm{p}=0.00003)$.

Serological parameters: cytokines and metalloproteinases. The concentration of the selected serological parameters was analyzed in 3 groups:

- patients diagnosed with Lyme borreliosis before the application of antibiotic therapy (38 subjects);

- foresters with anti-Borreliella IgG but with no clinical Lyme borreliosis symptoms (33 subjects, positive control); - foresters with no anti-Borreliella antibodies (24 subjects, negative control) (Tab. 3 and 4).

Analysis of the cytokines revealed that only the concentration of IL-2 was significantly higher $(2.4 \mathrm{pg} / \mathrm{ml} ; \mathrm{p}=0.00641)$ in the patients with Lyme borreliosis symptoms than in the seropositive individuals (positive control, $0.4 \mathrm{pg} / \mathrm{ml}$ ). The levels of IL-8, TNF, IL-6, and IL-4 in the serum samples collected from the patients with Lyme borreliosis symptoms, were higher than in the control groups, but these differences were not significant. There were no significant differences in the concentrations of the IP-10, MCP-1, MIG-1, and RANTES chemokines in the serum of the examined subjects.

The MMP2 concentration was significantly higher (233.3 ng/ml; p=0.00294) in the patients with clinical manifestations of Lyme borreliosis than in the subject that were occupationally exposed to tick bites but did not have anti-Borreliella antibodies (192.0 ng/ml). In turn, no significant differences were found in the concentration of this metalloproteinase between the patients and the seropositive individuals (with anti-Borreliella $\mathrm{IgG}$ ) presenting no clinical symptoms of the disease (MMP2-213.1 ng/ml). A similar trend was observed in the case of metalloproteinase MMP9; however, the differences in the values of this parameter between the analyzed groups did not have statistical significance.

\section{DISCUSSION}

According to the recommendations, specific clinical symptoms are a basis for the diagnosis of Lyme borreliosis, which must be confirmed by detection of specific antiBorreliella antibodies. The presence of anti-Borreliella antibodies without clinical signs of infection is not an indication for medical treatment [25], since some Borreliella antigen-seropositive subjects do not present clinical signs of disease [9-19].

Anti-Borreliella antibodies were detected in the sera of $57.9 \%$ of foresters occupationally exposed to tick bites, but did not report symptoms of Lyme borreliosis. The moment of tick attachment to the skin is not always noticed and therefore cannot be a decisive criterion for assessment of the risk of the disease. Studies conducted by Shkilna et al. [26] have shown that $70 \%$ of patients with clinical symptoms of Lyme borreliosis and current anti-Borreliella antibodies declared the occurrence of tick bites (single bites - 35\%, double bites 
Table 2. Anti-Borreliella IgG antibodies in patients with clinical manifestations of Lyme borreliosis (only those with advanced (IgM and IgG) and late anti-Borreliella response (only $\lg \mathrm{G})$ ) and seropositive foresters

\begin{tabular}{|c|c|c|c|c|c|c|c|c|c|c|c|c|}
\hline & \multicolumn{12}{|c|}{ Anti-Borreliella IgG antibodies } \\
\hline & p18* & p19 & p20 & p21 & $\mathrm{p} 25^{* *}$ & p39 & $\mathrm{p} 41^{* * *}$ & p58 & p83 & VlsE**** & Lba & Lbb \\
\hline $\begin{array}{l}\text { Patients with Lyme } \\
\text { borreliosis } \\
\mathrm{N}=36(100 \%)\end{array}$ & $5(13.9)$ & $7(19.4)$ & $2(5.6)$ & $6(16.7)$ & $15(41.7)$ & $9(25.0)$ & $36(100.0)$ & $6(16.7)$ & 11(30.6) & $36(100.0)$ & $3(8.3)$ & $2(5.6)$ \\
\hline $\begin{array}{l}\text { Seropositive foresters } \\
N=33(100 \%)\end{array}$ & $20(60.6)$ & $16(48.5)$ & - & $2(6.0)$ & $3(9.1)$ & $9(27.3)$ & $9(27.3)$ & - & $13(39.4)$ & $20(60.6)$ & - & - \\
\hline
\end{tabular}

* $-\mathrm{p}=0.00003 ; * *-p=0.00009 ; * * *-p=0.000001 ; * * * * \mathrm{p}=0.000001$

$\mathrm{N}$ - Number of people in the test group

Table 3. Concentrations of selected cytokines in Lyme borreliosis patients prior to treatment and in subjects occupationally exposed to tick bites

\begin{tabular}{|c|c|c|c|c|c|c|c|c|c|c|c|c|c|c|c|c|}
\hline & \multicolumn{16}{|c|}{ Parameter $[\mathrm{pg} / \mathrm{ml}]$} \\
\hline & $\mathrm{IL}-2$ & SD & IL-4 & SD & IL-6 & SD & IL-10 & SD & IL-17A & SD & INF-g & SD & TNF & SD & IL-8 & SD \\
\hline $\begin{array}{l}\text { Patients with symptoms of Lyme borreliosis } \\
\text { before deployment of treatment, } \mathrm{N}=38\end{array}$ & $2.4^{*}$ & 8.8 & 1.0 & 2.9 & 2.2 & 7.4 & 0.3 & 2.4 & 0.06 & 0.4 & 0.06 & 0.4 & 2.7 & 13.2 & 19.3 & 14.0 \\
\hline $\begin{array}{l}\text { People professionally exposed to tick } \\
\text { bites - IgG } B \text {. burgdorferi antibodies present } \\
\text { (positive control) } \mathrm{N}=33\end{array}$ & $0.4^{*}$ & 0.7 & 0.4 & 0.8 & 1.0 & 1.5 & 0.2 & 0.4 & 1.14 & 3.6 & 0.04 & 0.2 & 0.01 & 0.05 & 17.5 & 14.4 \\
\hline
\end{tabular}

(positive control) $\mathrm{N}=33$

People professionally exposed to tick bites

- no IgG B. burgdorferi antibodies present

(negative control)

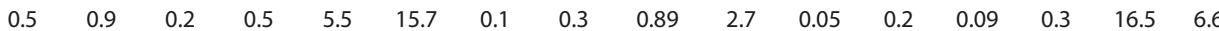

$\mathrm{N}=24$

* $p=0.00641$

$\mathrm{N}-$ The number of people in the test group

Table 4. Selected serological parameters in patients with Lyme borreliosis before implementation of treatment, and in people professionally exposed to tick bites

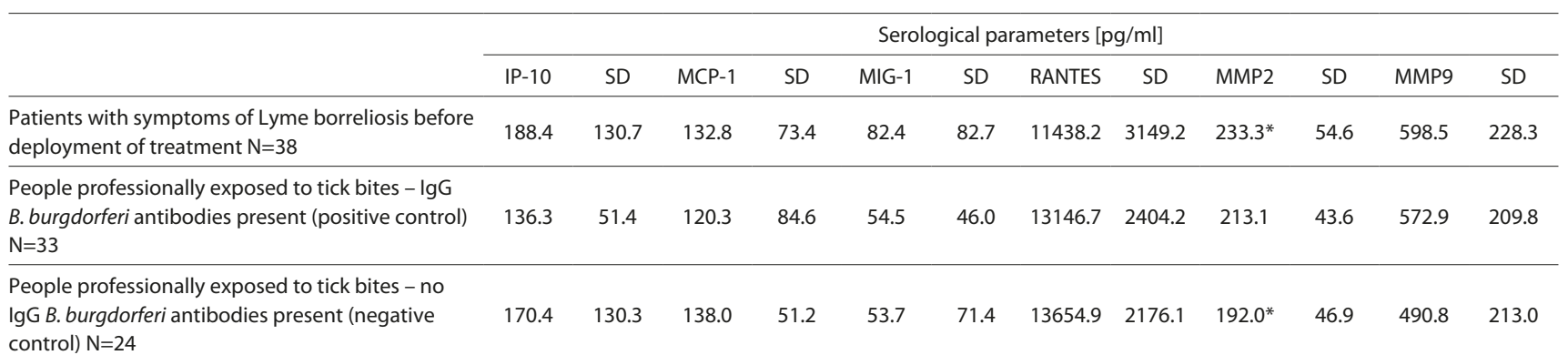

* $\mathrm{p}=0.00294$

$\mathrm{N}$ - Number of people in the test group

$-10 \%$, multiple bites $-25 \%)$. Other studies indicate that only $12.5 \%$ of rural residents bitten by ticks performed diagnostic tests to detect anti-Borreliella antibodies [27]. In the group of patients with Lyme borreliosis symptoms qualified for antibiotic therapy, 20\% did not notice a tick attached to their skin. These observations confirm that clinical symptoms combined with the presence of antibodies to specific antigenic proteins of LD group of Borreliaceae species are crucial in the diagnosis of Lyme borreliosis. Simultaneously, the absence of contact with a tick reported in a patient's medical history cannot be a decisive criterion. Great importance for the diagnosis of Lyme disease is attached to the quality of Borreliella antigens. The use of recombinant antigens (p100, p58, p41, VlsE, OspC, DbpA), especially in the Western blot test, instead of antigens from cell lysates, is diagnostically preferable $[7,25,28]$.

One of the most immunogenic Borreliella proteins is flagellin, which elicits a strong early humoral response. This protein shows a high degree of homology with the flagellin of Bacillus subtilis, Salmonella Typhimurium, T. pallium, Borrelia recurrentis, Borrelia duttoni, Borrelia hermsii, and Leptospira sp., hence the possibility of cross-reactions. Epitopes characteristic of Borreliella p41 are present only between amino acids 129 and 251, and only such a protein can be regarded as a specific antigen of the spirochete with diagnostic importance [29]. The interpretation of the Western blot results took into account the presence of antibodies against diagnostically important Borreliella antigens: early phase markers (OspC, VlsE), highly specific p39 antigen (BmpA), late phase markers (p83, lipid markers), and recombinant antigens (p58, p21, p20, p19, and p18). Analysis of IgG antibodies in patients with advanced (IgM and IgG) or late (only IgG) anti-Borreliella and in the seropositive foresters showed significantly greater frequency of anti-VlsE and p25 IgG antibodies in the patients. In turn, anti-p18 IgG were significantly more prevalent in the sera from the 
seropositive foresters than in the patients. Therefore, it seems that the type of immunological reactions has key importance in the development of the symptomatic form of infection, especially in chronic cases.

Clinical manifestations of Lyme borreliosis may be associated with the ineffectiveness of host immune mechanisms to eliminate the pathogen, development of autoimmune reactions, or immunopathological mechanisms related to cytokine production [10]. The LD group of Borreliaceae species are able to stimulate immunocompetent cells for production of both pro-inflammatory and antiinflammatory cytokines $[30,31]$ and activation of CD14 mononuclear cells. In turn, this leads to the production of TNF- $\alpha$, INF- $\alpha$, IL-1, IL-6, IL-8, IL-12, chemokines, and reactive oxygen species and, consequently, has an impact on the further production of cytokines, chemokines, and molecules with adhesive and signaling functions [21]. Chemokines play an important role in the generation of inflammatory response in tissues during Borreliella infection. Early induction of macrophages and dendritic cells to secrete CCL3 (a chemoattractant for monocytes, natural killer cells, and T cells) and CCL4 (a chemoattractant for monocytes and some T cells) is indispensable for initiation of the migration of inflammatory cells. Species causing LD directly influences CD14+ monocytes/macrophages via induction of secretion of CCL3, CCL4, and CXCL8 (a neutrophil chemoattractant) and stimulation thereof to secrete CCL2 with the help of IFN- $\gamma$. Additionally, IFN- $\gamma$ induces secretion of CXCL9 and CXCL10 by these cells [32]. Chemokine IP-10 (CXCL10) is secreted by leukocytes, neutrophils, eosinophils, monocytes, endothelial cells, and keratinocytes in response to IFN- $\gamma$. CXCL10 exerts a strong effect on biological functions, chemotactic activity, apoptosis, and regulation of cell growth and proliferation. It also plays an important role in infectious and cancer diseases; however, the mechanism of CXCL10 interactions in the pathogenesis of infectious, viral, and bacterial diseases has not been fully elucidated. It is known that impaired production of CXCL10 may lead to, e.g., increased susceptibility to Legionella pneumophila and Candida albicans infection. IP-10 has been shown to play a role in Helicobacter pylori, Mycoplasma, and Chlamydia infections [33]. The role of CXCL10 in Lyme borreliosis has not been demonstrated to-date.

Skogman et al. [14] found no differences in the number of Borreliella -specific IFN- $\gamma$-, IL-4-, and IL-17-secreting cells when comparing Borreliella-exposed asymptomatic children, patients with clinical Lyme borreliosis and a control group. Neither were significant differences found in the Borreliella-induced cytokine secretion (IL-1 $\beta$, IL-6, IL-10, TNF) between the groups in this study. As shown by Ekerfelt et al. [10], seropositive subjects without clinical Lyme borreliosis symptoms had a similar number of Borreliellaspecific IFN-producing cells as patients with symptomatic Borreliella infection. The authors suggest that IFN- $\gamma$ acting as part of a set of cytokines produced in response to infection rather than alone, may play a role in elimination of Borreliella spirochetes. As demonstrated in other studies, IL- 6 is able to induce IL-17 secretion from naive T cells and, therefore, together with IL-17 may be involved in the inflammatory mechanisms and pathogenesis of Lyme borreliosis [34, 35].

Research carried out by Zhi et al. [36] in an animal model have shown that $\mathrm{Clqa}^{-/-}$mice with impaired activation of the classical complement pathway exhibit altered Th1/Th2 response balance after infection with B. burgdorferi B31. Elevated levels of cytokines produced by Th1 (MIP-1a, IL-2, IL-12, and TNFa), Th2 (IL-4, IL-10 and MCP -1), and Th17 (IL-17), were detected in the infected $\mathrm{Clqa}^{-/-}$mice. Clq has been shown to affect cytokine production associated with both $\mathrm{T}$ cell and $\mathrm{B}$ cell responses in B. burgdorferi infection [36]. It cannot be excluded that these relationships can affect the quality and intensity of anti-Borreliella responses.

In the presented study, there were no statistically significant correlations between the concentrations of IL- 6 and IL-17A, IFN- $\gamma$, IL-4, IL-8, and IL-10 in the Lyme borreliosis patients, compared with the Borreliella-seropositive subjects (positive control) and those with no such antibodies (negative control). However, a significantly higher concentration of IL-2 and a higher, although statistically insignificant, level of TNF were noted in the patients with Lyme borreliosis symptoms.

In their studies, Sjöwall et al. [37] and Jarefors et al. [38] did not show significant differences in the production of IL$1 \beta$, IL- 6 , IL-10, TNF, and IFN- $\gamma$ by PBMC between groups of patients with neuroborreliosis symptoms, asymptomatic Borreliella-seropositive subjects, and seronegative individuals. As shown by Cerar et al. [39], the serum levels of cytokines (IL-1 $\beta$, IL-2, IL-4, IL-5, IL-6, IL-10, IL-12, TNF- $\alpha$, and IFN- $\gamma$ ) and chemokine IL-8 did not differ between patients with clinical neuroborreliosis symptoms and those with suspected neuroborreliosis. In contrast, serum CXCL13 chemokine levels were higher in the patients with neuroborreliosis. The elevated levels of chemokine CXCL13 in the cerebrospinal fluid were shown to be significantly associated with intrathecal synthesis of Borreliella antibodies. Burgasova et al. [40] reported higher levels of IL-2, IL-4, and IL-8 in patients with Lyme borreliosis during the acute phase; however, the IL-4 and IL-2 levels in patients with arthritis remained high during the recovery phase.

Analysis of the serum samples collected from the symptomatic Lyme borreliosis patients, as well as the seropositive and control subject, did not reveal significant differences in the levels of chemokines IP-10, MCP-1, MIG-1, and RANTES. However, there was a significant difference in the serum MMP2 metalloproteinase levels in the untreated patients with Lyme borreliosis symptoms $(233.3 \mathrm{ng} / \mathrm{ml})$, compared to those determined in the seronegative individuals $(192.0 \mathrm{ng} / \mathrm{ml})$. Similarly, the MMP9 levels in the patients with Lyme borreliosis symptoms were higher but not statistically significant in comparison with the results in the seronegative individuals (negative control). It is possible that the immune response to $B$. burgdorferi infection increases serum MMP2 levels. Metalloproteinases, including MMP2 and MMP9, may be important for the degenerative processes developing in Lyme borreliosis. MMP-2 is active against collagen type I, II, and MCP-3 chemokine, whereas MMP-9 has affinity for plasminogen, myelin, and cartilage proteoglycans [23, 24, 41]. As reported by Zhao et al. [21], the serum MMP9 concentration in patients with acute Lyme borreliosis is significantly higher than in healthy controls. Determination of MMP2 and MMP9 in a larger group of patients and control groups, including subjects occupationally exposed to tick bites, could confirm or exclude the observed relationship and show the potential importance of this parameter for monitoring the development and suppression of the infection. 


\section{CONCLUSIONS}

1. The failure to notice a tick bite by a patient suspected of Lyme borreliosis cannot be a decisive criterion for exclusion from the need to carry out serological tests.

2. The presence of IgG antibodies against a number of Borreliella antigens and the differences in the IL-2 and MMP2 levels in seropositive or seronegative individuals and symptomatic Lyme borreliosis patients, may indicate differences in the intensity of the immune response to the infection and, consequently, may induce development of clinical manifestations of the disease in seropositive and seronegative individuals.

3. Studies on a larger group of patients with clinical symptoms of Lyme borreliosis and seropositive subjects focused on innate defense mechanisms, e.g. the complement system, will prove or exclude their significance.

\section{Competing interests}

The authors declare that they have no competing interests.

\section{Funding}

This work was funded by the Pope John Paul II State School of Higher Education in Biala Podlaska; "Analysis of the immune response to Borrelia burgdorferi infection in patients treated for Lyme disease" [grant number IV,2016]; "Analysis of the secretion of selected cytokines and chemokines in patients with Lyme borreliosis" [grant number S_11_17, 20017].

\section{Acknowledgements}

We are grateful to Adam Szepeluk for technical assistance in statistical analysis.

\section{REFERENCES}

1. Barbour AG, Adeolu M, Gupta RS. Division of the genus Borrelia into two genera (corresponding to Lyme disease and relapsing fever groups) reflects their genetic and phenotypic distinctiveness and will lead to a better understanding of these two groups of microbes (Margos et al. (2016) There is inadequate evidence to support the division of the genus Borrelia. Int J Syst Evol Microbiol. doi: 10.1099/ijsem.0.001717). Int J Syst Evol Microbiol. 2017; 67(6): 2058-2067. https:/doi.org/10.1099/ ijsem. 0.001815

2. Stanek G, Strle F. Lyme borreliosis - from tick bite to diagnosis and treatment. FEMS Microbiol Rev. 2018; 42(3): 233-258. https://doi. org/10.1093/femsre/fux047

3. Stanek G, Wormser GP, Gray J, Strle F. Lyme borreliosis. Lancet. 2012; 379: 461-473. https://doi.org/10.1016/S0140-6736(11)60103-7

4. Steere AC, Strle F, Wormser GP, Hu LT, Branda JA, Havius JW, et al. Lyme borreliosis. Nat Rev Dis Primers. 2016; 2: 16090. https://doi. org/10.1038/nrdp. 2016.90

5. Stanek G. Lyme borreliosis, ticks and Borrelia species. Wien Klin Wochenschr. 2018; 130: 459-462. https://doi.org/10.1007/s00508-0181376-2

6. Eldin C, Raffetin A, Bouiller K, Hansmann Y, Roblot F, Raoult D, et al. Review of European and American guidelines for the diagnosis of Lyme borreliosis. Med Mal Infect. 2019; 49(2): 121-132. https://doi. org/10.1016/j.medmal.2018.11.011

7. Pancewicz SA, Garlicki AM, Moniuszko-Malinowska A, Zajkowska J, Kondrusik M, Grygorczuk S, et al. Polish Society of Epidemiology and Infectious Diseases. Diagnosis and treatment of tick-borne diseases recommendations of the Polish Society of Epidemiology and Infectious Diseases. Przegl Epidemiol. 2015; 69(2): 309-316.

8. Stanek G, Fingerle V, Hunfeld KP, Jaulhac B, Kaiser R, Krause A, et al. Lyme borreliosis: clinical case definitions for diagnosis and management in Europe. Clin Microbiol Infect. 2011; 17: 69-79. https:// doi.org/10.1111/j.1469-0691.2010.03175.x
9. Dehnert M, Fingerle V, Klier C, Talaska T, Schlaud M, Krause G, et al. Seropositivity of Lyme Borreliosis and Associated Risk Factors: A Population-Based Study in Children and Adolescents in Germany (KiGGS). PLoS ONE 2012; 7(8): e41321. https://doi.org/10.1371/journal. pone.0041321

10. Ekerfelt C, Forsberg P, Svenvik M, Roberg M, Bergstrom S, Ernerudh J. Asymptomatic Borrelia-seropositive individuals display the same incidence of Borrelia-specific interferon-gamma (IFN-g)secreting cells in blood as patients with clinical Borrelia infection. Clin Exp Immunol. 1999; 115: 498-502. https://doi.org/10.1046/j.13652249.1999.00840.x

11. Hjetland R, Nilsen RM, Grude N, Ulvestad E. Seroprevalence of antibodies to Borrelia burgdorferi sensu lato in healthy adults from western Norway: risk factors and methodological aspects. APMIS. 2014; 122(11): 1114-1124. https://doi.org/10.1111/apm.12267

12. Hristea A, Hristescu S, Ciufecu C, Vasile A. Seroprevalence of Borrelia burgdorferi in Romania. Eur J Epidemiol. 2001; 17: 891-896. https:// doi.org/10.1023/a:1015600729900

13. Pańczuk A, Kozioł-Montewka M, Tokarska-Rodak M. Exposure to ticks and seroprevalence of Borrelia burgdorferi among a healthy young population living in the area of southern Podlasie, Poland. Ann Agric Environ Med. 2014; 21(3): 512-517. https://doi. org/10.5604/12321966.1120593

14. Skogman BH, Hellberg S, Ekerfelt C, Jenmalm MC, Forsberg P, Ludvigsson $\mathrm{J}$, et al. Adaptive and innate immune responsiveness to Borrelia burgdorferi sensu lato in exposed asymptomatic children and children with previous clinical Lyme borreliosis. Clin Dev Immunol. 2012; 2012: 294587. https://doi.org/10.1155/2012/294587

15. Steere AC, Sikand VK, Schoen RT, Nowakowski J. Asymptomatic infection with Borrelia burgdorferi. Clin Infect Dis. 2003; 37: 528-532. https://doi.org/10.1086/376914

16. Tomao P, Ciceroni L, D’Ovidio MC, De Rosa M, Vonesch N, Iavicoli $S$, et al. Prevalence and incidence of antibodies to Borrelia burgdorferi and to tick-borne encephalitis virus in agricultural and forestry workers from Tuscany, Italy. Eur J Clin Microbiol Infect Dis. 2005; 24: 457-463. https://doi.org/10.1007/s10096-005-1348-0

17. Wilhelmsson P, Fryland L, Lindblom P, Sjöwall J, Ahlm C, Berglund $\mathrm{J}$, et al. A prospective study on the incidence of Borrelia burgdorferi sensu lato infection after a tick bite in Sweden and on the Åland Islands, Finland (2008-2009). Ticks Tick Borne Dis. 2016; 7: 71-79. https://doi. org/10.1016/j.ttbdis.2015.08.009

18. Wilking H, Fingerle V, Klier C, Thamm M, Stark K. Antibodies against Borrelia burgdorferi sensu lato among Adults, Germany, 2008-2011. Emerg Infect Dis. 2015; 21(1): 107-110. https://doi.org/10.3201/ eid2101.140009

19. Zákutná L, Dorko E, Rimárová K, Kizeková M. Pilot Cross-Sectional Study of Three Zoonoses (Lyme Disease, Tularaemia, Leptospirosis) among Healthy Blood Donors in Eastern Slovakia. Cent Eur J Public Health. 2015; 23(2): 100-106. https://doi.org/10.21101/cejph.a4052

20. Pancewicz S, Rutkowski R, Rutkowski K, Zajkowska JM, Kondrusik M. Immunopathology of Lyme arthritis. Pol Merkur Lek. 2007; 23(134): 141-144.

21. Zhao Z, Fleming R, McCloud B, Klempner MS. CD14 Mediates Cross Talk between Mononuclear Cells and Fibroblasts for Upregulation of Matrix Metalloproteinase 9 by Borrelia burgdorferi. Infect Immun. 2007; 75(6): 3062-3069. https://doi.org/10.1128/IAI.00202-07

22. Zajkowska JM, Pancewicz SA, Grygorczuk S, Kondrusik M, Moniuszko A, Lakwa K. Neuroborreliosis - some aspects of pathogenesis, diagnosis and treatment. Pol Merkur Lek. 2008; 24(143): 453-457.

23. Baszczuk A, Kopczyński Z, Thielemann A, Musialik K, Kopczyński J, Bielawska L, et al. Evaluation of concentrations of metalloproteinase 2 (MMP-2) and metalloproteinase 9 (MMP-9) in serum of patients with primary hypertension. Forum Zab Metabol. 2015; 6(2): 74-84.

24. Lipka D, Boratyński J. Metalloproteinases. Structure and function. Postepy Hig Med Dosw. (online) 2008; 62: 328-336. http://www.phmd. $\mathrm{pl} / \mathrm{api} /$ files/view/2768.pdf (accessed 15 March 2018).

25. Chmielewski T, Dunaj J, Gołąb E, Gut W, Horban A, Pancewicz S, et al. Diagnostyka laboratoryjna chorób odkleszczowych. Krajowa Izba Diagnostów Laboratoryjnych, Warszawa, 2014. https://kidl.org. pl/file/file/get?id=150_05kleszcze-z-okladka.pdf (access: 2018.03.02).

26. Shkilna M, Tokarska-Rodak M, Pańczuk A, Smiyan S, Andreychyn M, Klishch I, et al. The use of anti-C6VlsE IgG in the assessment of the effectivness of Lyme disease treatment - a preliminary report. Health Probl Civiliz. 2019; 13(1): 83-91. https://doi.org/10.5114/hpc.2019.81106

27. Dankiewicz K, Tokarska-Rodak M, Weiner M. Prophylaxis of Lyme borreliosis and rural residents' awareness. Health Probl Civiliz. 2018; 12(1): 1-6. https://doi.org/10.5114/hpc.2017.69028 
28. Krzemień PJ. Role of VlsE/C6 antigen as a marker for early Lyme borreliosis diagnosis and monitoring the effectiveness of its treatment Health Probl Civiliz. 2017; 11(2): 87-92. https://doi.org/10.5114/ hpc.2017.69023

29. Aguero-Rosenfeld ME, Wang G, Schwarz I, Womser GP. Diagnosis of Lyme borreliosis. Clin Microbiol Rev. 2005; 18(3): 484-509. https://doi. org/10.1128/CMR.18.3.484-509.2005

30. Diterich I, Härter L, Hassler D, Wendel A, Hartung T. Modulation of Cytokine Release in Ex Vivo-Stimulated Blood from Borreliosis Patients Infect Immun. 2001; 69(2): 687-694. https://doi.org/10.1128/ IAI.69.2.687-694.2001

31. Kisand KE, Prükk T, Kissand KV, Lüüs SM, Kalbe I, Uibo R. Propensity to excessive proinflammmatory response in chronic Lyme borreliosis. APMIS. 2007; 115: 134-141. https://doi.org/10.1111/j.1600-0463.2007. apm_538.x

32. Shin JJ, Strle K, Glickstein LJ, Luster AD, Steere AC. Borrelia burgdorferi stimulation of chemokine secretion by cells of monocyte lineage in patients with Lyme arthritis. Arthritis Res Ther. 2010; 12(5): R168. https://doi.org/10.1186/ar3128

33. Liu M, Guo S, Hibbert JM, Jain V, Singh N, Wilson NO, et al. CXCL10/ IP-10 in Infectious Diseases Pathogenesis and Potential Therapeutic Implications. Cytokine Growth Factor Rev. 2011; 22(3): 121-130. https:// doi.org/10.1016/j.cytogfr.2011.06.001

34. Nordberg M, Forsberg P, Johansson A, Nyman D, Jansson C, Ernerudh J, et al. Cytotoxic mechanisms may play a role in the local immune response in the central nervous system in neuroborreliosis. J Neuroimmunol 2011; 232(1): 186-193. https://doi.org/10.1016/j.jneuroim.2010.09.028
35. Sallusto F, Lanzavecchia A. Human Th17 cells in infection and autoimmunity. Microbes Infect. 2009; 11(5): 620-624. https://doi. org/10.1016/j.micinf.2009.04.004

36. Zhi H, Xie J, Skare JT. The Classical Complement Pathway Is Required to Control Borrelia burgdorferi Levels During Experimental Infection. Front Immunol. 2018; 9: 959. https://doi.org/10.3389/fimmu.2018.00959

37. Sjöwall J, Carlsson A, Vaarala O, Bergström S, Ernerudh J, Forsberg PC, et al. Innate immune response in Lyme borreliosis: enhanced tumor necrosis factor- $\alpha$ and interleukin-12 in asymptomatic individuals in response to live spirochetes. Clin Exp Immunol. 2005; 141: 89-98. https://doi.org/10.1111/j.1365-2249.2005.02820.x

38. Jarefors S, Bennet L, You E, Forsberg P, Ekerfelt C, Berglund J, et al. Lyme borreliosis reinfection: might it be explained by a gender difference in immune response? Immunology. 2006; 118: 224-232. https://doi.org/10.1111/j.1365-2567.2006.02360.x

39. Cerar T, Ogrinc K, Lotrič-Furlan S, Kobal J, Levičnik-Stezinar S, Strle F, et al. Diagnostic Value of Cytokines and Chemokines in Lyme Neuroborreliosis. Clin Vaccine Immunol. 2013; 20(10): 1578-1584. https://doi.org/10.1128/CVI.00353-13

40. Burgasova OA, Uskov AN, Grichenko NE, Tseneva GIa. Features of cytokine levels in serum of patients with tick-borne borreliosis with different clinical signs. Zh Mikrobiol Epidemiol Immunobiol. 2010; 3: $67-71$.

41. Urbaniak J, Dybaś E, Krajewska M, Weyde W, Klinger M, Woźniak M. The assessment of usefulness of gelatin zymography for metalloproteinase 9 (MMP-9) determination in plasma. Diagn Lab. 2007; 43: 657-667. 